Article

\title{
Mapping Forest Biomass Using Remote Sensing and National Forest Inventory in China
}

\author{
Ling Du ${ }^{1,2}$, Tao Zhou ${ }^{1,2, *}$, Zhenhua Zou ${ }^{2,3}$, Xiang Zhao ${ }^{4}$, Kaicheng Huang ${ }^{1,2}$ and Hao Wu ${ }^{1,2}$
}

1 State Key Laboratory of Earth Surface Processes and Resource Ecology,

Beijing Normal University, Beijing 100875, China; E-Mails: lingdu@mail.bnu.edu.cn (L.D.); huangkaicheng@mail.bnu.edu.cn (K.H.); wuhaogis@163.com (H.W.)

2 Academy of Disaster Reduction and Emergency Management, Ministry of Civil Affairs and Ministry of Education, Beijing 100875, China; E-Mail: zouzhenhua@mail.bnu.edu.cn

3 Key Laboratory of Environmental Change and Natural Disaster of MOE, Beijing Normal University, Beijing 100875, China

4 College of Global Change and Earth System Science, Beijing Normal University, Beijing 100875, China; E-Mail: zhaoxiang@bnu.edu.cn

* Author to whom correspondence should be addressed; E-Mail: tzhou@bnu.edu.cn; Tel./Fax: +86-10-5880-7508.

Received: 21 January 2014; in revised form: 19 April 2014 / Accepted: 29 May 2014 / Published: 11 June 2014

\begin{abstract}
Quantifying the spatial pattern of large-scale forest biomass can provide a general picture of the carbon stocks within a region and is of great scientific and political importance. The combination of the advantages of remote sensing data and field survey data can reduce uncertainty as well as demonstrate the spatial distribution of forest biomass. In this study, the seventh national forest inventory statistics (for the period 2004-2008) and the spatially explicit MODIS Land Cover Type product (MCD12C1) were used together to quantitatively estimate the spatially-explicit distribution of forest biomass in China (with a resolution of $0.05^{\circ}, \sim 5600 \mathrm{~m}$ ). Our study demonstrated that the calibrated forest cover proportion maps allow proportionate downscaling of regional forest biomass statistics to forest cover pixels to produce a relatively fine-resolution biomass map. The total stock of forest biomass in China was $11.9 \mathrm{Pg}$ with an average of $76.3 \mathrm{Mg} \mathrm{ha}^{-1}$ during the study period; the high values were located in mountain ranges in northeast, southwest and southeast China and were strongly correlated with forest age and forest density.
\end{abstract}


Keywords: biomass; forest inventory; remote sensing; forest cover proportion; spatial distribution

\section{Introduction}

Forest biomass acts as an important indicator of carbon resources and carbon sequestration potential in terrestrial systems [1]. Estimates of forest biomass enable a direct measurement of carbon storage and provide initial values for process-based carbon cycle models to simulate carbon dynamics [2]. Mapping the spatial pattern of large-scale forest biomass can provide a general picture of the carbon stocks within a region and is of great scientific and political importance. China is one of the biggest forestry nations in the world and has possessed a large area of reforestation and afforestation during past decades, which significantly affects the carbon cycle of the terrestrial ecosystem $[3,4]$. Thus, characterizing its size and spatial distribution is necessary to understand the current carbon storage of China and to contribute to further carbon sequestration studies and the promotion of better stewardship of the forests.

Different approaches have been applied to forest biomass estimation. Traditionally, field measurements are the most accurate methods for estimation. However, these approaches are usually time consuming and labor intensive, and also cannot provide the continuous spatial distribution of biomass at large scales [5]. Remote sensing enables the estimation of forest biomass at multiple scales with large spatial and temporal coverage. Correlations between spectral information detected by remote sensing and forest biomass are used in forest biomass estimation. However, it remains a challenge to establish the correlation because of the complexity of canopy characteristics and the uncertainty of remote sensing information [6]. Recently, with the ability to detect the structures of forest, radar and lidar remote sensing are also used to estimate forest biomass. However, there remain limitations in typical study areas and they have not been applied extensively to large scale studies because of cost constraints $[7,8]$.

Given the different advantages of different data, an appropriate combination of multi-source data, such as the field measurement and the remote sensing monitoring, can potentially improve spatially explicit estimates of biomass over large areas [6,9]. In recent years, the method of combining remote sensing with field measurements has been applied in the Europe and North America to estimate large-scale forest biomass or other forest parameters, and retains the advantages of the accuracy of field measurements and the advantages of the spatial distribution of remote sensing [7,10-13]. Kindermann et al. produced a consistent global spatial database at half degree resolution containing forest growing stock, biomass and carbon stock values using a relationship between net primary productivity (NPP) and biomass and the relationship between human impact and biomass [13].

However, when comparing remote sensing data and field measurements, discrepancies are apparent between some forest characteristics (such as forest area and volume) assessed using field measurements and the same characteristics estimated using remote sensing images [13-15]. Traditionally, a pixel in a remote sensing image is entirely classified as forest or others, which probably leads to systematic underestimation or overestimation of forest characteristics. In contrast with remote sensing, the ground-based field measurements are more accurate. Although the advantage of combining 
satellite-based remote sensing and ground-based field measurement is obvious, it is usually difficult to conduct due to the different spatial resolutions. Päivinen et al. [16,17] developed a methodology to adjust the NOAA-based forest cover proportion map to match statistics from the forest inventory and ultimately produced a growing stock map of Europe. The forest cover proportion map represents the forest area proportion within a pixel, which reflects the actual forest cover objectively, and has been used in other studies [18-20].

In China, most research focused on using forest inventory statistics to estimate total forest biomass to further explore carbon sinks or sources lacking image-based spatial information [21-25], and large uncertainties still existed in some related researches [14,26]. In this study, our aim is to estimate a spatially-explicit biomass map from inventory statistics using spatially-explicit satellite data. We spatially downscaled the forest biomass map of China at $0.05^{\circ}(\sim 5600 \mathrm{~m})$ resolution using a calibrated forest cover proportion map derived from MODIS MCD12C1 product, which produced a good match with regional forest inventory statistics.

\section{Data and Methods}

The seventh national forest inventory statistics and the spatially explicit MODIS Land Cover Type product (MCD12C1.051) were utilized in this study. In addition, the map of China's administrative division was applied to link the statistical data of national forest inventory and the MODIS land cover type product.

\subsection{Data}

\subsubsection{Forest Inventory Data}

The systematical national forest inventory has been conducted nearly every five years since the late 1970s and the seventh national forest inventory was conducted for the period 2004-2008. The statistics of the national forest inventory in China are based on large numbers of field plots (e.g., 415,000 plots for the seventh national forest inventory) and are the most important data sources in research on forest carbon storage and carbon sinks. We obtained the seventh national forest inventory statistics from the Forest Resources Statistics of China provided by the Forest Resources Management Department of the State Forestry Administration.

The seventh national forest inventory statistics are categorized into three groups: forest stand, economic forest and bamboo forest. It documents the areas and timber volumes by individual tree species and stand ages in each province for forest stands, and only the forest area in each province for economic and bamboo forests. In this study, we used the statistics of forest stand including forest area and timber volume represented by individual tree species and stand ages in 31 provinces. The forest area statistics were used to calibrate the MODIS Land Cover data and the timber volume statistics were used to estimate the forest biomass. Note that forest in Hong Kong, Macao and Taiwan was not included in this study due to the lack of data. 


\subsubsection{MODIS Land Cover Data}

The MODIS Land Cover Type Yearly Climate Modeling Grid (MCD12C1.051 product) was obtained from [27] with a $0.05^{\circ}(\sim 5600 \mathrm{~m})$ spatial resolution, which provides the dominant land cover types and the sub-grid frequency distribution of each land cover class. The product is based on a full year of composited eight-day MODIS observations (reflectance and land-surface temperature) and can be considered representative for the state of the land surface. It contains three classification schemes and we used the primary land cover scheme, International Geosphere Biosphere Programme (IGBP). Each pixel has the sub-grid frequency value for 17 land cover classes, the sum of which totals 100 . Table 1 lists the IGBP land cover classification system, five categories of which were related to forest land cover: (1) evergreen needleleaf forests; (2) evergreen broadleaf forests; (3) deciduous needleleaf forests; (4) deciduous broadleaf forests; and (5) mixed forests. We summed the sub-grid frequency of the five forest categories for each year (2004-2008) and thus yearly forest cover maps were available.

Table 1. International Geosphere Biosphere Programme (IGBP) land cover classification types.

\begin{tabular}{cccc}
\hline Class & Type & Class & Type \\
\hline 0 & Water & 9 & Savannas \\
1 & Evergreen Needleleaf forest & 10 & Grasslands \\
2 & Evergreen Broadleaf Forest & 11 & Permanent Wetlands \\
3 & Deciduous Needleleaf Forest & 12 & Croplands \\
4 & Deciduous Broadleaf Forest & 13 & Urban and Built-Up Lands \\
5 & Mixed Forest & 14 & Cropland/Natural Vegetation Mosaic \\
6 & Closed Shrublands & 15 & Snow and Ice \\
7 & Open Shrublands & 16 & Barren or sparsely vegetated \\
8 & Woody Savannas & 17 & Fill Value/Unclassified \\
\hline
\end{tabular}

\subsection{Methods}

In this study, we spatially downscaled the forest biomass of China at $0.05^{\circ}(\sim 5600 \mathrm{~m})$ resolution using a calibrated forest cover proportion map combining remote sensing data and forest inventory data. This study utilized the methods of Päivinen et al. [16], with amendments for applicability to Chinese forest ecosystems. Figure 1 presents the methodology in this study. The procedure consists of three phases: (1) computation of forest biomass; (2) forest area calibration process; and (3) downscaling of forest biomass.

\subsubsection{Preparation of Biomass Statistics}

We used the conversion factor continuous function method [21] to convert timber volume to biomass for individual tree species in each province. The function was expressed as Equation (1). Forest biomass was summed at both provincial and national levels for the seventh national forest inventory statistics.

$$
B=\mathrm{a} V+\mathrm{b}
$$

where $B$ is forest biomass $(\mathrm{Mg}) ; V$ is timber volume of individual tree species in each province $\left(\mathrm{m}^{3}\right) ; \mathrm{a}, \mathrm{b}$ are coefficients for different tree species outlined in Fang et al. [21,25]. For the newly added tree species in the seventh national forest inventory statistics, the coefficients refer to the most similar tree species. 
Figure 1. Flow chart for mapping forest biomass.

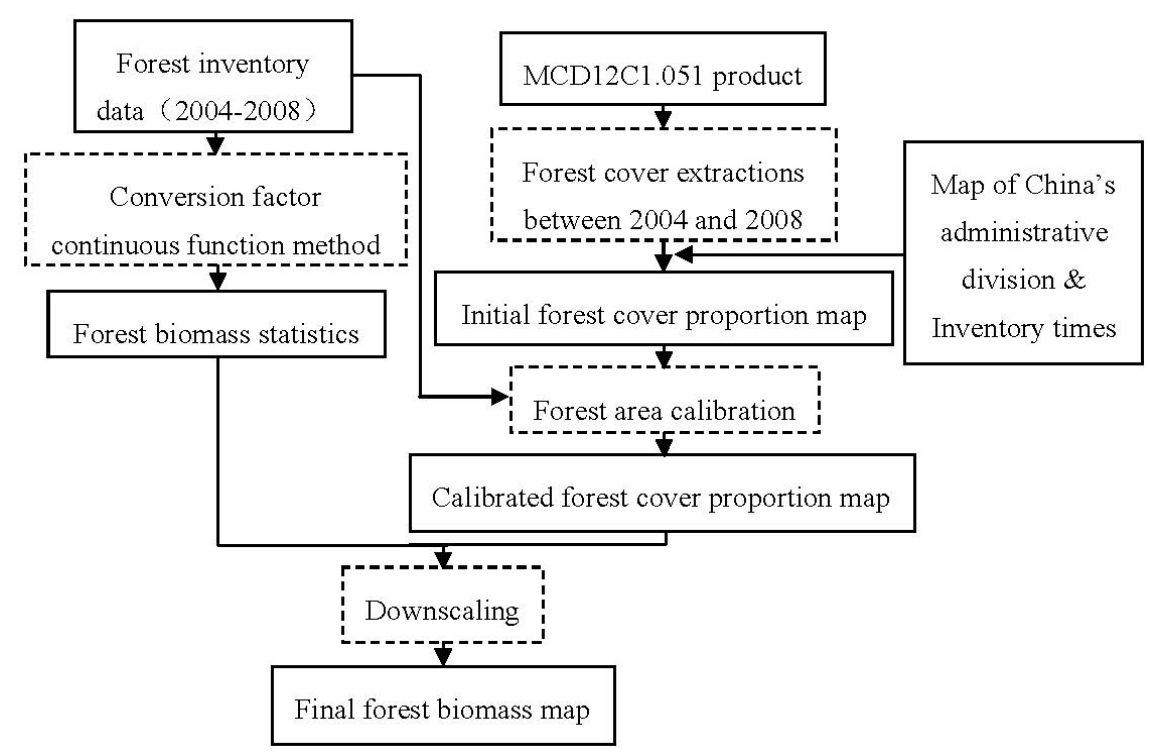

\subsubsection{Forest Area Calibration Process}

The aim of the forest area calibration process was to reduce the discrepancies between forest inventory and MODIS land cover products regionally, which retains the advantages of both the accuracy of forest inventory and the spatial distribution of remote sensing. The forest area calibration process refers to Paivinen et al. methods [16,17]. The authors classified land cover types into three categories (coniferous forest, broadleaf forest and other land) and ultimately produced a calibrated forest cover proportion map which matched forest inventory statistics regionally.

Considering the limited accuracy and different forest definitions of the MODIS land cover data [28,29], we classified land cover types in a pixel into two categories (forest and non-forest), which was more applicable to Chinese complex forest ecosystems. We summed the sub-grid frequency of the five forest categories from the MCD12C1.051 for each year (2004-2008), and obtained forest cover maps for each year with the pixel value ranging from $0 \sim 100$. However, in this study, the specific forest inventory times for different provinces are not the same during the inventory period (Figure 2). To enable the distribution of forest cover from remote sensing and the forest statistics from the inventory data to be spatiotemporally consistent, provincial forest cover maps were extracted according to different inventory times based on the Map of China's administrative division. Thus, the initial forest cover proportion map of each province was produced with the pixel value transformed to percentage $(0 \% \sim 100 \%)$. Furthermore, corresponding non-forest cover proportion map of each province was also available through subtraction. At last, each province has two variable layers corresponding to forest and non-forest cover types, and the sum of which totals $100 \%$ per pixel. All the proportion maps were transformed to Albers equal area projection for further forest area calibration. 
Figure 2. Specific forest inventory times for each province from 2004-2008.

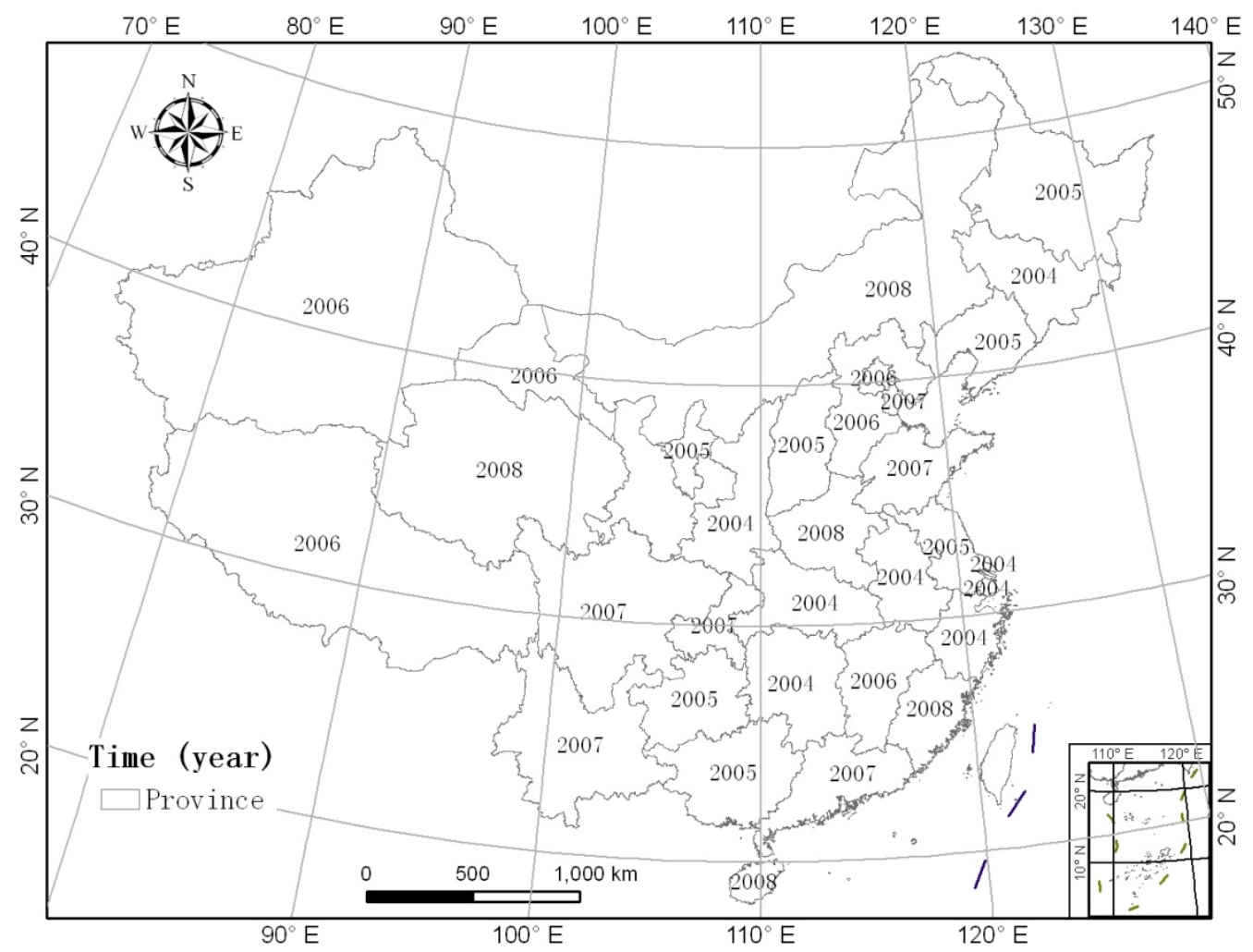

The algorithm of the forest area calibration process was expressed as Equations (2)-(8). The main idea of the algorithm was to match the mean forest coverage estimated from image within a region to that from the inventory statistics as much as possible through adjusting the forest and non-forest cover proportion in each pixel. In this study, the procedure was conducted per province.

$$
\begin{gathered}
\bar{x}^{(a)}=\frac{\sum_{i=1}^{n} x^{(a)}(i)}{n} \\
\mathcal{W}^{(a)}=\frac{X^{(a)}}{\bar{x}^{(a)}} \\
x_{r}^{(a)}(i)=w^{(a)} x^{(a)}(i) \\
s(i)=\sum_{\mathrm{a}=1}^{2} x_{r}^{(a)}(i) \\
x_{\mathrm{rs}}^{(a)}(i)=\frac{1}{s(i)} x_{r}^{(a)}(i) \\
\bar{x}_{r s}^{(a)}=\frac{\sum_{i=1}^{n} x_{\mathrm{rs}}^{(a)}(i)}{n} \\
\operatorname{diff}^{(a)}=\bar{x}_{r s}^{(a)}-X^{(a)}
\end{gathered}
$$


where, $a$ represents the land over type (forest or non-forest); $i$ represents pixel; $n$ is the total number of the pixels in the image of the calibration province; $x^{(a)}(i)$ is the proportion for the land cover type $a$ in a pixel $(i)$ in the image of the calibration province; $x^{-(a)}$ represents the image-estimated mean coverage for the land cover type $a$ in the province; $X^{(a)}$ is the accurate mean forest or non-forest coverage based on inventory statistics, which was calculated as the ratio of total forest or non-forest area obtained from inventory statistics to the land area calculated from the image of the calibration province; $W^{(a)}$ is the adjust coefficient to match the coverage estimate from image to statistics; $x_{r}^{(a)}(i)$ is the adjusted proportion for the land cover $a$ in a pixel $(i) ; S(i)$ is the sum of the calibrated proportions of the two land cover types in a pixel $(i)$; To confirm the sum value is $100 \%$ for each pixel, the sum value is scaled by deriving a ratio for each pixel: $1 / S(i) ; x_{\mathrm{rs}}^{(a)}(i)$ is the calibrated and scaled proportion estimate for land cover type $a$ in a pixel $(i) . \bar{x}_{r s}^{(a)}$ is the recalculated image-estimated mean coverage for the land cover type $a$ in the province. diff ${ }^{(a)}$ represents the difference between forest coverage estimated from calibrated image and that from the inventory statistics.

This algorithm is repeated until the chosen threshold value $\operatorname{diff}{ }^{(a)}$ is reached and the pixel sums are equal to $100 \%$. In this study, the threshold value was set as $0.3 \%$ of the value $X^{(a)}$ from statistics for all provinces [16]. If the iteration reached 100, the calibration was stopped to prevent consuming time with the provinces that could not be calibrated or were not close to the value from the statistics. The national calibrated forest cover proportion map was available when the process was stopped for all provinces.

\subsubsection{Downscaling}

Upon completion of the forest area calibration process, the calibrated forest cover proportion map that matched the inventory statistics on absolute forest area provincially was available. We proposed that the forest biomass density was directly proportional to forest area cover within a pixel. Thus, calibrated forest cover proportion maps can effectively reflect the spatial distribution of biomass and allow downscaling of regional forest biomass from statistics to pixels in an image, following Equation (9). Furthermore, the downscaling process was also conducted per province.

$$
B_{\mathrm{rs}}^{(a)}(i)=\frac{B^{(a)}}{A^{(a)}} x_{\mathrm{rs}}^{(a)}(i)
$$

where $a$ only stands for forest type; $B_{\mathrm{rs}}^{(a)}(i)$ is the forest biomass in a pixel $(i)\left(\mathrm{Mg} \mathrm{ha}^{-1}\right) ; B^{(a)}$ is the total forest biomass of a province from the statistics $(\mathrm{Mg}) ; A^{(a)}$ is the forest area of a province estimated from the calibrated map (ha), which also matched the inventory statistics; $x_{\mathrm{rs}}^{(a)}(i)$ is the calibrated and scaled forest proportion estimate in a pixel $(i)$.

\section{Results and Discussion}

\subsection{Calibration of Forest Area}

Before the calibration process, we found that the total forest area at national levels obtained from the forest inventory and that from the MODIS forest cover were similar, $15.6 \times 10^{7}$ ha and $15.7 \times 10^{7}$ ha, respectively. However, when comparing the forest areas at provincial levels, the values differed strongly 
(Figure 3). For example, the absolute forest area of Jiangsu province was $0.7 \times 10^{6}$ ha from inventory statistics but $0.3 \times 10^{6}$ ha from the forest cover map; the absolute forest area of Yunnan province was $14.7 \times 10^{6}$ ha from inventory statistics but $19.9 \times 10^{6}$ ha from the forest cover map. After the calibration process, the regional discrepancies between forest inventory statistics and images were generally reduced. The calibration results were satisfactory and the absolute forest area estimates between them were nearly the same at both provincial and national levels (Figure 3).

Figure 3. Comparison of forest areas using the forest inventory and the forest cover proportion map derived from the MODIS product at the province level.

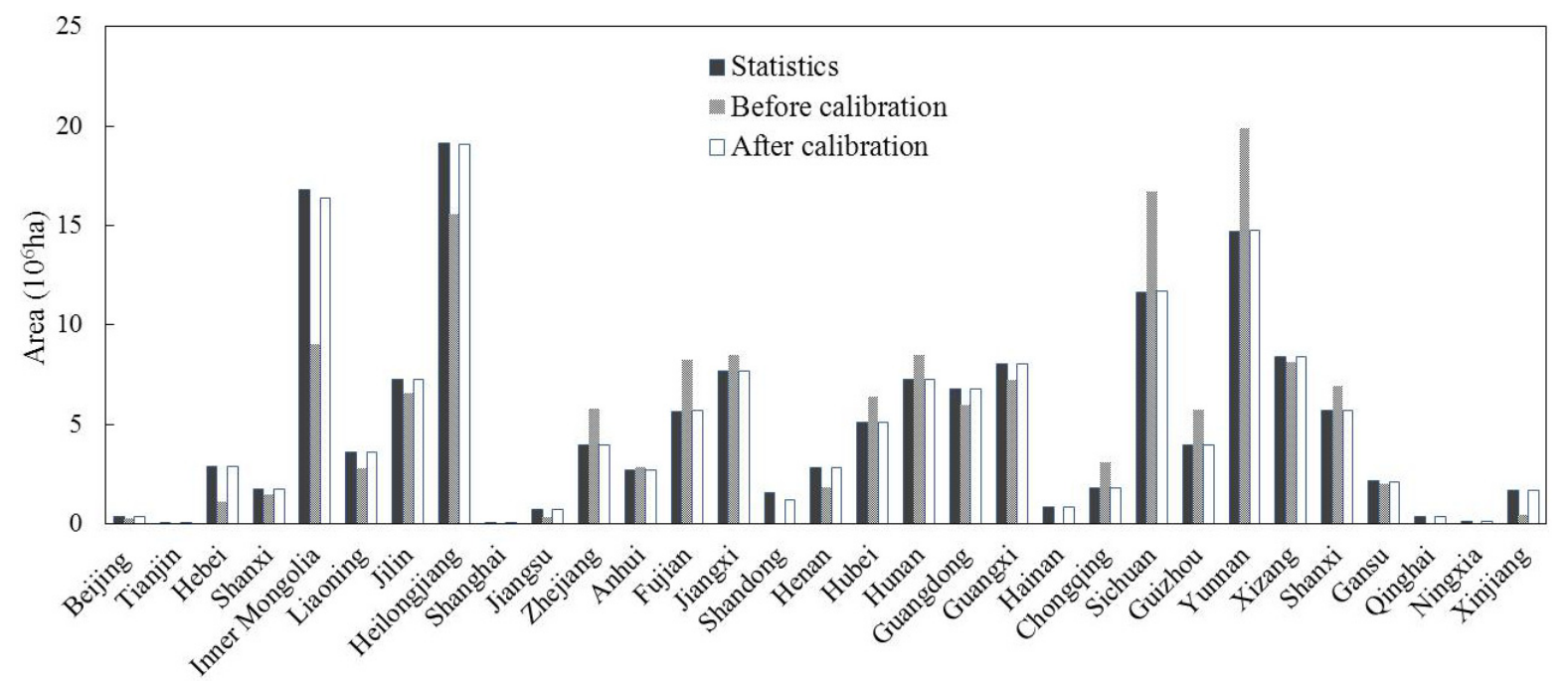

All provinces were calibrated successfully except Inner Mongolia and Shandong provinces, where the iteration reached 100. In these two provinces, there were too few forest pixels to meet the forest area of the statistics, and all forest pixel values were adjusted to $100 \%$ to match the statistics as much as possible.

\subsection{Downscaling}

Downscaling technology is used to transform large-scale, coarse resolution information into regional-scale, high resolution information, which is widely applied in many other related fields $[13,14,30,31]$. In general, forest inventory statistics can provide coarse resolution information, but remote sensing can reflect the spatially explicit information of forests at a high resolution. Forest biomass density was directly proportional to forest coverage within one pixel. In this study, we calculated the average biomass density and corresponding forest coverage in each province based on the inventory statistics and found a good relationship between forest biomass and forest coverage at the provincial scale (Figure 4). We spatially downscaled biomass statistics from the forest inventory based on a forest cover proportion map derived from remote sensing products at $0.05^{\circ}(\sim 5600 \mathrm{~m})$ resolution.

Figure 5 is the schematic diagram for downscaling forest biomass using Guangdong province as an example. Figure $5 \mathrm{a}$ is the total forest biomass estimated from the inventory statistics that provide the coarsest information at the provincial level. Using the forest cover derived from the MODIS product (Figure 5b), the average biomass density at forest-cover level was available (Figure 5c). Combining the average biomass density map and the calibrated forest cover proportion map (Figure 5d), we produced the distribution of forest biomass at the sub-pixel level (Figure 5e). 
Figure 4. Relationship between forest coverage and biomass in China.

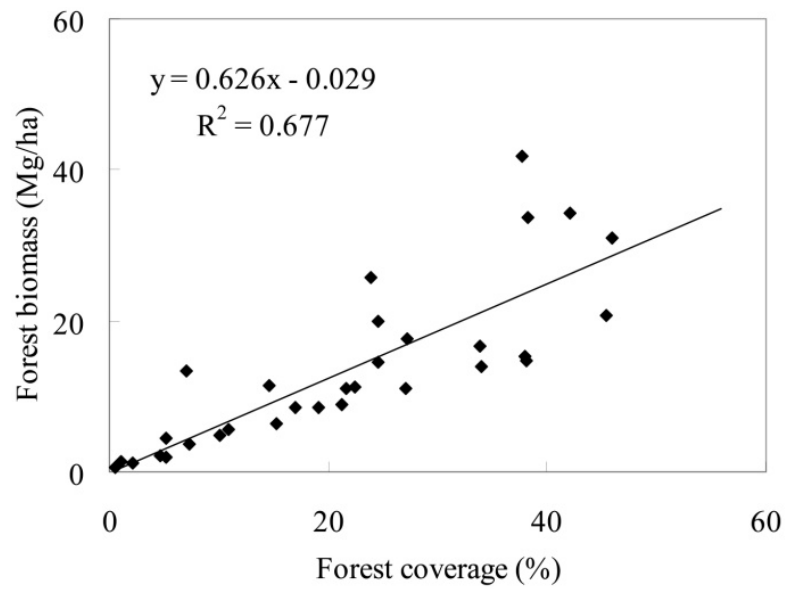

Figure 5. Schematic diagram for downscaling forest biomass (Guangdong province). (a) Total forest biomass obtained from the statistics (provincial level); (b) Forest cover derived from the MODIS product; (c) The average biomass density distribution (forest-cover level); (d) The calibrated forest cover proportion map; (e) The distribution of forest biomass (sub-pixel level).

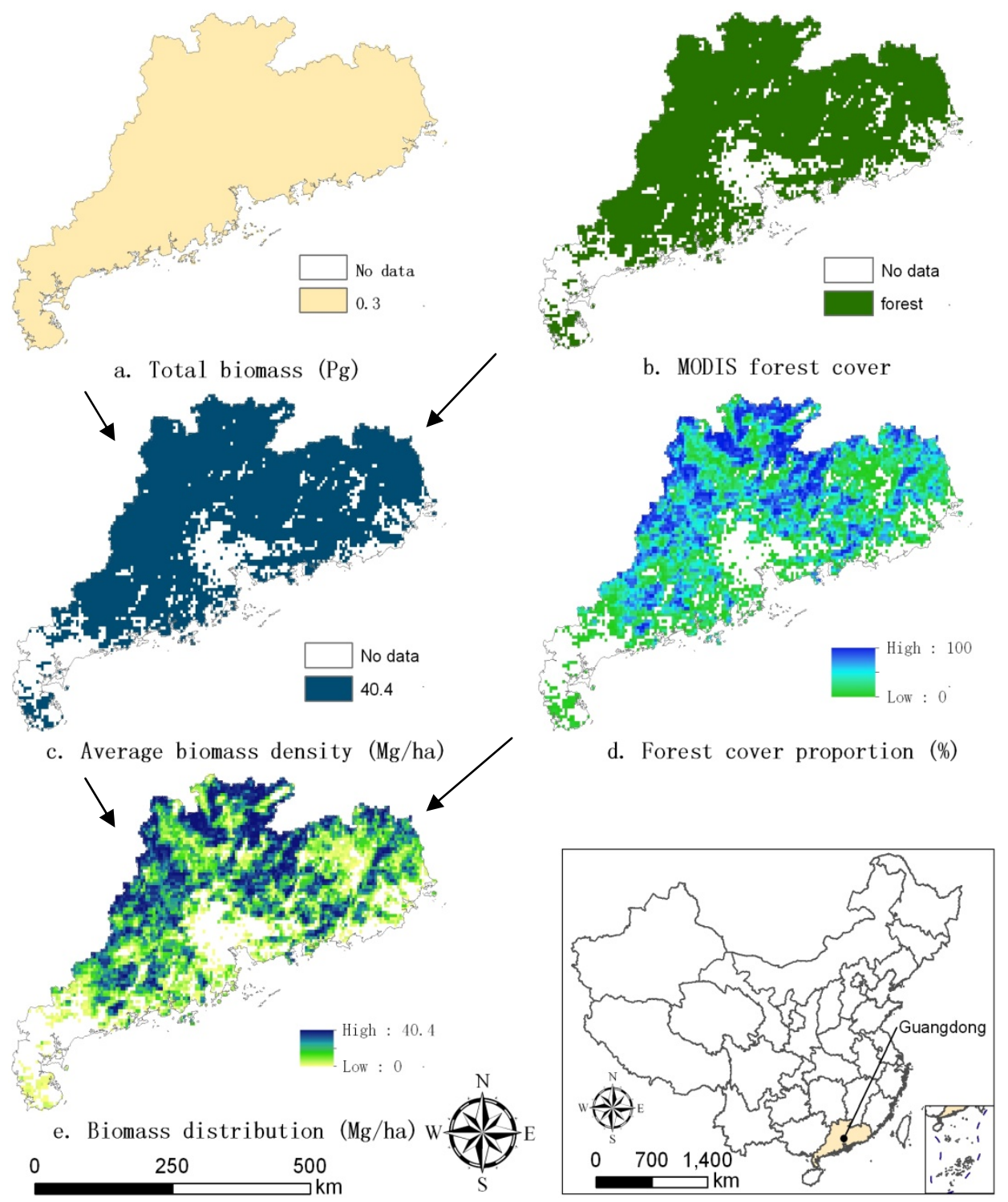




\subsection{Spatial Distribution of Biomass}

The total storage of forest biomass was $11.9 \mathrm{Pg}$, with an average of $76.3 \mathrm{Mg} \mathrm{ha}^{-1}$, which increased slightly compared to the biomass storage in the sixth national forest inventory statistics [14]. It suggests that the forest ecosystem in China represents a carbon sink. Figure 6 represents the final, downscaled spatial distribution of forest biomass in China. Overall, we found that forest biomass was mainly distributed in the northeastern, southwestern and southeastern areas of China; high biomass density was located in the Da Hinggan, Xiao Xing'an and Changbai mountains of the northeast, the Tianshan mountains of the west, the Qinling and Hengduan mountains of the southwest and the Wuyi mountains of the southeast.

Figure 6. Spatial distribution of forest biomass in China for the period 2004-2008.

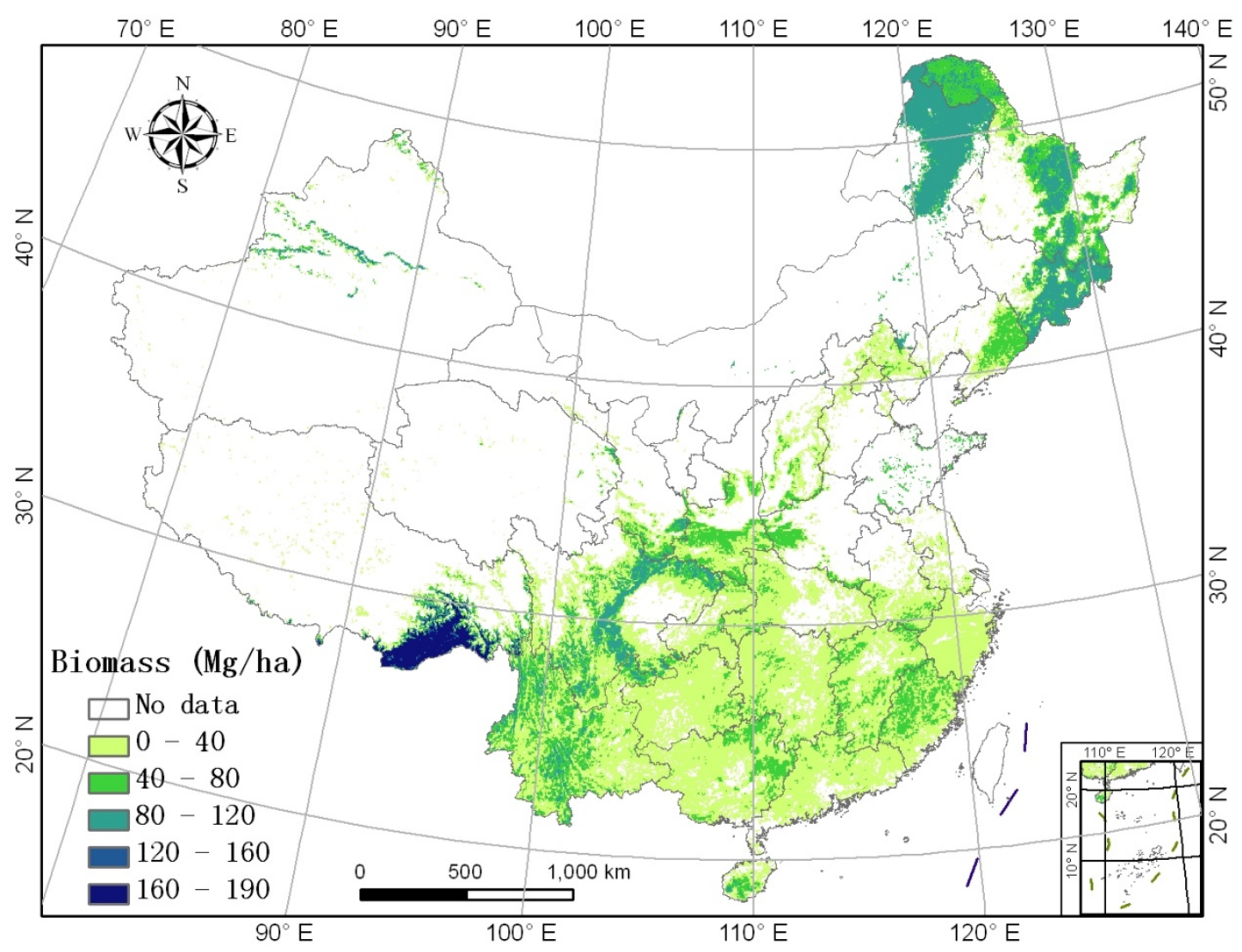

The forest biomass density in the southeast was relatively lower than that of the southwest and the northeast for several reasons. First, recent studies have found that the forests of southeast China are younger than those of the rest the country [31], and biomass has been found to increase with forest stand age $[32,33]$. Second, human activities mainly occur in southeastern China, and there is a high degree of urbanization, perhaps causing a lower forest density. However, in the large mountain ranges with less human disturbance, mainly located in southwest and northeast China, the forest density is high. Moreover, several ecological restoration projects in China including the Natural Forest Conservation Program, the Three-North Projective Forest Program and the South China Timber Production Program were mainly implemented in the southwest and the northeast, thus largely promoting the accumulation of forest biomass [34]. 


\subsection{Accuracy Assessment}

To illustrate the impact of the calibration method, we compared the calibrated forest cover and biomass maps against the initial forest cover and biomass maps which had not been processed by forest area calibration, as shown in Figure 7. Figure 7a,b is initial and calibrated forest cover proportion maps, respectively, and the corresponding biomass maps produced are shown in Figure $7 \mathrm{c}, \mathrm{d}$. The difference of biomass distribution was extracted through the subtraction of the two biomass maps (Figure 7e). We found that the calibration method had a large effect on the reallocation of forest area and then on biomass. Additionally, large overestimation or underestimation of forest cover proportion and biomass remains in mountain ranges, mainly because in China the boundaries of administrative zones are commonly along mountains, so the spatially contiguous forests in some mountains may be located in different administrative zones.

Figure 7. The difference of biomass distribution based on initial and calibrated forest cover proportion maps. (a) Initial forest cover proportion (\%); (b) calibrated forest cover proportion (\%); (c) biomass before calibration $(\mathrm{Mg} / \mathrm{ha})$; (d) biomass after calibration (Ma/ha); (e) difference (Ma/ha).

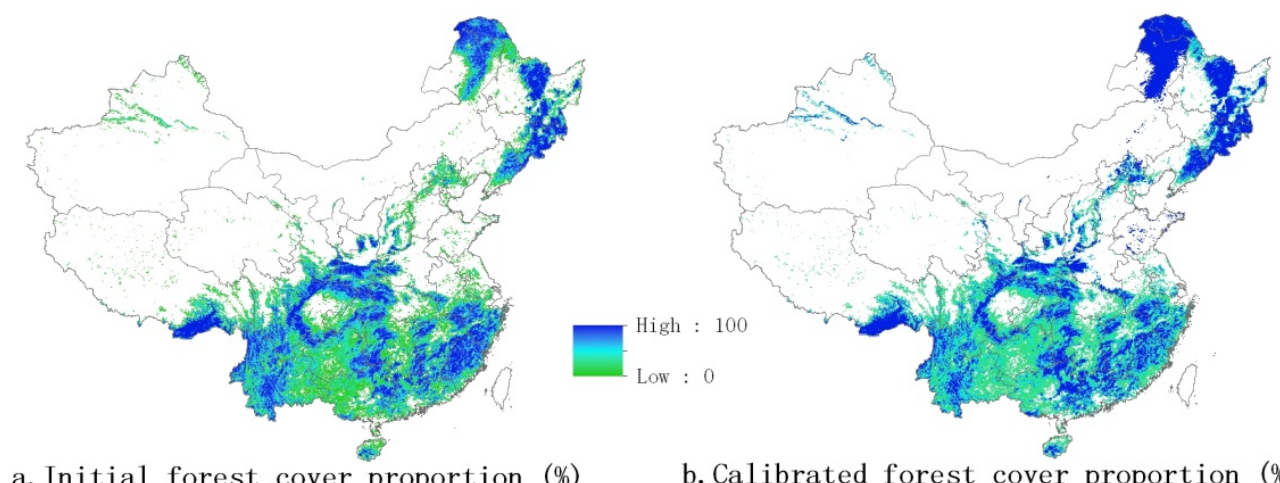

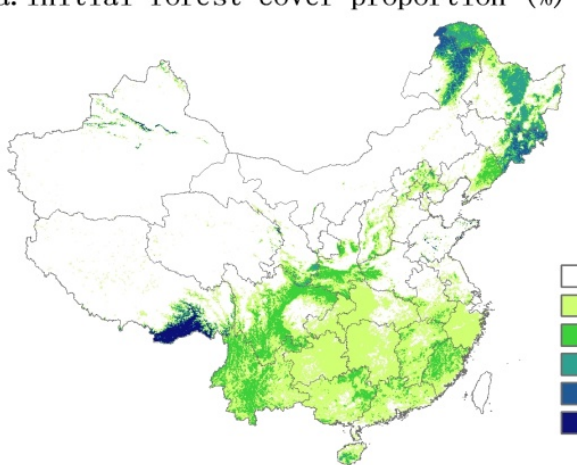

c. Biomass before calibration $(\mathrm{Mg} / \mathrm{ha})$

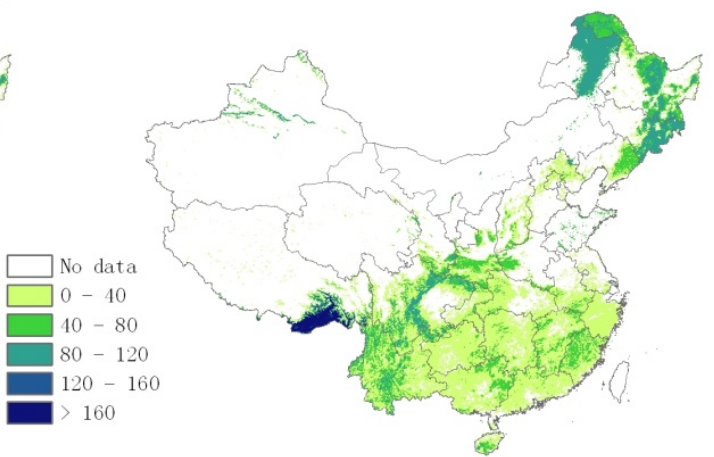

d. Biomass after calibration $(\mathrm{Mg} / \mathrm{ha})$
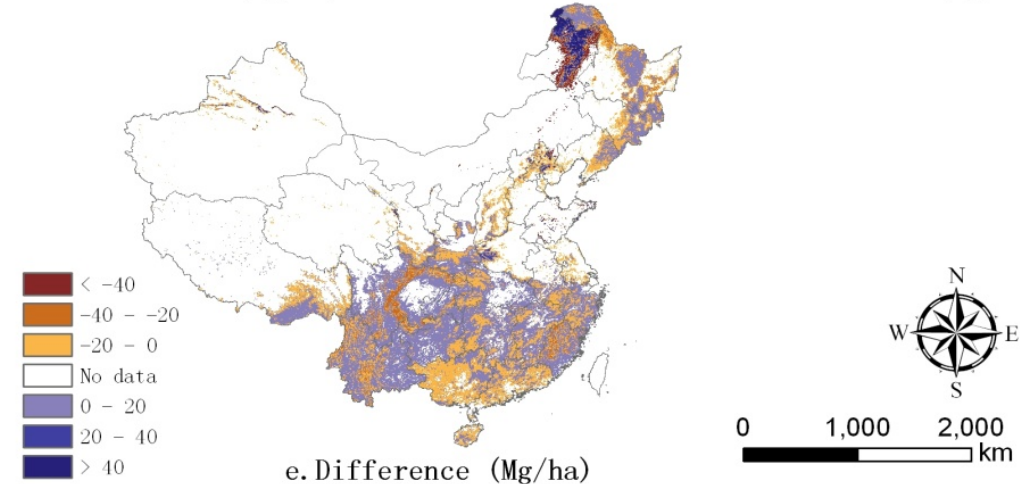

e. Difference $(\mathrm{Mg} / \mathrm{ha})$

0 
To independently validate the accuracy of the method, a leave-one-out validation strategy was conducted. We iteratively calibrated the MODIS forest cover area of each province using a mean calibrated coefficient derived from the remaining provinces. Thus, a new set of calibrated forest biomass estimates was available based on the simulated forest cover estimates which were totally independent of the inventory statistics. Figure 8 shows the relationship between average forest biomass in each province using leave-one-out method and that using inventory statistics. It illustrated that they have a good consistency. The validation of leave-one-out also indicated that our calibration tactic in this study, i.e., independent calibration for each province using its own inventory statistics and corresponding MODIS estimate, is a good choice that could diminish the deviations of MODIS product in different provinces.

Figure 8. The relationship between average forest biomass using leave-one-out method and that using inventory.

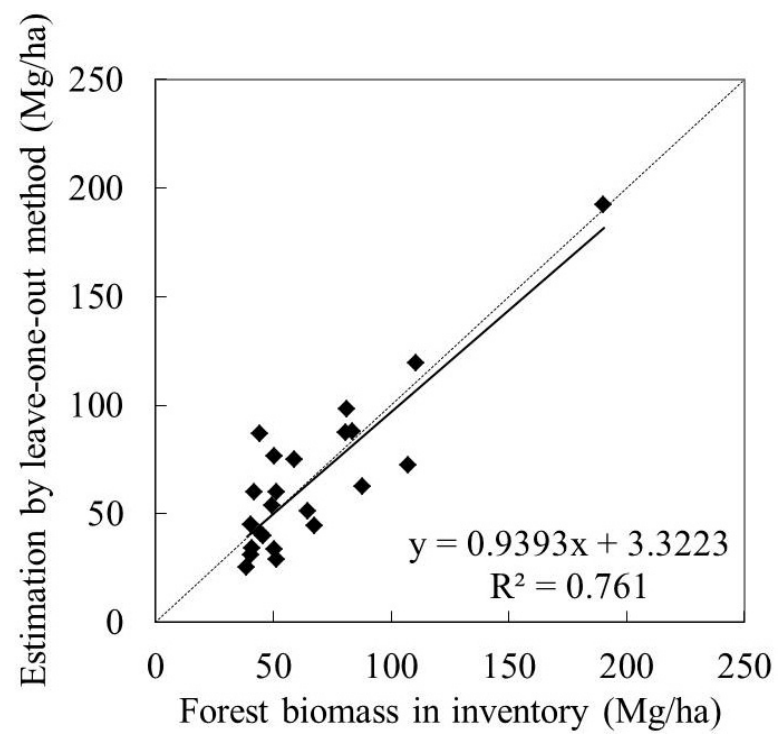

To quantitatively analyze the accuracy of our biomass results, we compared our results with the previous study of Guo et al. [24] (Figure 9). Figure 9a compares average forest biomass density of each province in this study and that of Guo et al. Figure 9b shows an improved match between absolute forest area in the statistics and that in our results. Our biomass estimates matched the previous study very well — as indicated by the trend lines, mainly due to the successful forest area calibration process. Since the calibration method was implemented, the discrepancies of forest area between the remote sensing data and the national inventory decreased apparently (Figure 9b), which therefore significantly improved the accuracy of estimated biomass (Figure 9a).

To collate the general spatial distribution of the calibrated forest cover and biomass distribution in this study, we compared our results with the thematic map of growing stock, which was demonstrated to be highly related to biomass [24] in the Atlas of Forest Resources of China [35], and we found that the spatial pattern of our biomass matches well with the thematic map of growing stock. 
Figure 9. Accuracy assessment. (a) Comparison of forest biomass in the present study and in the literature; (b) Comparison of forest area before and after the calibration.
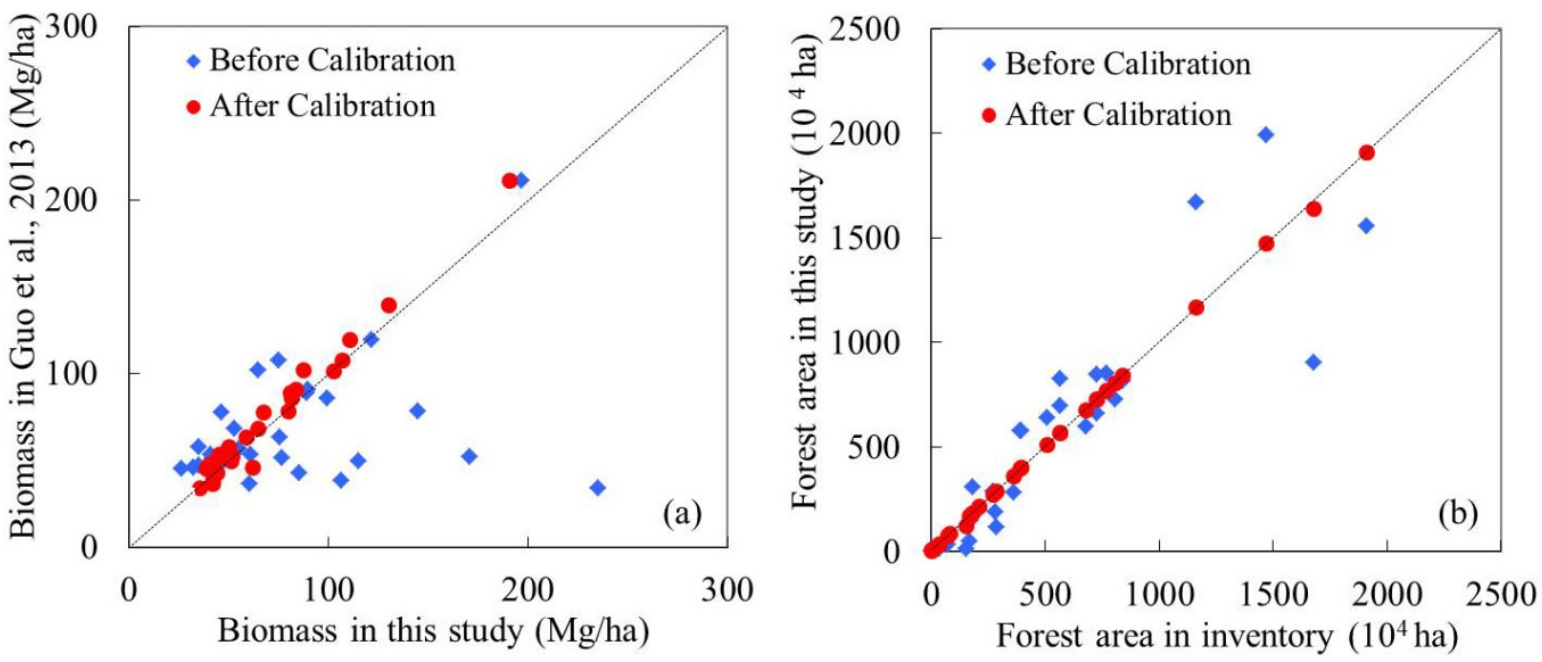

\subsection{Uncertainty}

In this study, forest area and biomass from the statistics of national forest inventory were used as constraints to calibrate the satellite-based forest cover map and forest biomass map and, therefore, diminished their potential system deviation. The forest area calibration process overcomes the traditional phenomenon of systematic underestimation in sparsely forested areas and overestimation in dense forest regions. However, the limitation of this method is that the algorithm was conducted within each province individually, which could introduce some abrupt changes in pixel-values along provincial borderlines where continuous forests may exist, and amplify the subsequent biomass estimation between the neighboring provinces.

In ideal situations (i.e., the deviations between the remote sensing-based and ground-based values are the same for all spatial grids), we can logically scale the provincial MODIS forest cover to match the inventory statistics using a single calibration factor (i.e., analytic method). This analytic method is simple and easy to conduct, but it is only applicable to ideal situations or small geographic regions where the spatial heterogeneity can be ignored. In this study, we applied an iteration method, which is somewhat complex in calculation, but it is applicable to most real situations or large geographic regions. The benefits of this iteration method are that it makes the absolute forest areas between the MODIS estimates and the inventory statistics as comparable as possible and, at the same time, guarantees the calibrated land cover proportions in all pixels within a reasonable range (i.e., 0 100\%).

During the forest area calibration processes, all provinces were calibrated successfully except for two; i.e., Inner Mongolia and Shandong, where the number of forest pixels in the satellite-based map was too small to meet the forest area in the statistics of national inventory. In addition, the chosen threshold value diff ${ }^{(a)}$ has some impacts on the application of the calibration process and a more flexible threshold enables a more flexible calibration. The results derived from leave-one-out validation indicated that the system deviations among different provinces are somewhat different. That is, the coefficients of scaling transformation originated from some provinces (e.g., forest widely distributed) maybe not completely applicable to the others (e.g., forest sporadically distributed). As a result, more attention 
needs to be paid to the spatial heterogeneity of geographic regions. If more geographic information such as forest net primary production and human activities were used, the precision of the biomass map may be improved further.

Previous studies [36] indicated that the conversion factor continuous function method had a high variability, which may affect the biomass estimates and mapping. Moreover, the coefficients for the newly added tree species in the seventh national forest inventory statistics referred to the most similar tree species, which may have some subjectivity. The $0.05^{\circ}(\sim 5600 \mathrm{~m})$ resolution of the forest biomass map produced in this study maybe still too coarse and finer-scale forest cover data may be helpful in the future. Moreover, no validation process was implemented to test the accuracy of the biomass at pixel-level within regions. If plot-level forest inventory statistics at the similar scale are available in the future, the validation process will be possible.

\section{Conclusions}

The objective of this study is to produce a spatially-explicit forest biomass map that matches actual forest biomass inventory data. In this study, the seventh national forest inventory statistics (for the period 2004-2008) and the spatially explicit MODIS Land Cover Type product (MCD12C1) were combined to quantitatively estimate the spatial distribution of forest biomass in China (with a resolution of $0.05^{\circ}, \sim 5600 \mathrm{~m}$ ). The results indicated that the total stock of forest biomass in China was $11.9 \mathrm{Pg}$ with an average of $76.3 \mathrm{Mg} \mathrm{ha}^{-1}$; the high values were found in mountain ranges in the northeast, southwest and southeast, which were strongly correlated with forest age and forest density. The study also demonstrated that the calibrated forest cover proportion maps allow proportionate downscaling of regional forest statistics to forest cover pixels to produce a relatively fine-resolution biomass map.

\section{Acknowledgments}

The authors appreciate two anonymous reviewers for their constructive suggestions on the improvements of the revised manuscript. This work was supported by the Fund for Creative Research Groups of National Natural Science Foundation of China (No. 41321001), the National Basic Research Program of China (No. 2012CB955401), the National Natural Science Foundation of China (No. 30970514), and the New Century Excellent Talents in University (No. NCET-10-0251).

\section{Author Contributions}

The paper was written by Ling Du with a significant contribution by Tao Zhou. Ling Du and Tao Zhou are responsible for the overall research design and conducted most of the work. Zhenhua Zou contributed to the implementation of forest area calibration. Xiang Zhao, Kaicheng Huang and Hao $\mathrm{Wu}$ assisted to result analysis and provide valuable suggestions.

\section{Conflicts of Interest}

The authors declare no conflict of interest. 


\section{References}

1. Le Toan, T.; Quegan, S.; Davidson, M.W.J.; Balzter, H.; Paillou, P.; Papathanassiou, K.; Plummer, S.; Rocca, F.; Saatchi, S.; Shugart, H.; et al. The BIOMASS mission: Mapping global forest biomass to better understand the terrestrial carbon cycle. Remote Sens. Environ. 2011, 115, 2850-2860.

2. Terrestrial Essential Climate Variables for Climate Change Assessment, Mitigation and Adaptation; Sessa, R., Dolman, H., Eds.; FAO GTOS-52: Rome, Italy, 2008; p. 40. Available online: http://www.fao.org/gtos/doc/pub52.pdf (accessed on 12 January 2014).

3. Wang, B.; Wang, D.; Niu, X. Past, present and future forest resources in China and the implications for carbon sequestration dynamics. J. Food Agric. Environ. 2013, 11, 801-806.

4. Piao, S.; Fang, J.; Ciais, P.; Peylin, P.; Huang, Y.; Sitch, S.; Wang, T. The carbon balance of terrestrial ecosystems in China. Nature 2009, 458, 1009-1013.

5. Brown, S. Measuring carbon in forests: Current status and future challenges. Environ. Pollut. 2002, 116, 363-372.

6. Lu, D.S. The potential and challenge of remote sensing-based biomass estimation. Int. J. Remote Sens. 2006, 27, 1297-1328.

7. Ji, L.; Wylie, B.K.; Nossov, D.R.; Peterson, B.; Waldrop, M.P.; McFarland, J.W.; Rover, J.; Hollingsworth, T.N. Estimating aboveground biomass in interior Alaska with Landsat data and field measurements. Int. J. Appl. Earth Obs. Geoinfor. 2012, 18, 451-461.

8. Rauste, Y. Multi-temporal JERS SAR data in boreal forest biomass mapping. Remote Sens. Environ. 2005, 97, 263-275.

9. Goetz, S.J.; Baccini, A.; Laporte, N.T.; Johns, T.; Walker, W.; Kellndorfer, J.; Houghton, R.A.; Sun, M. Mapping and monitoring carbon stocks with satellite observations: A comparison of methods. Carbon Balance Manag. 2009, 4, doi:10.1186/1750-0680-4-2.

10. Wulder, M.A.; White, J.C.; Fournier, R.A.; Luther, J.E.; Magnussen, S. Spatially explicit large area biomass estimation: Three approaches using forest inventory and remotely sensed imagery in a GIS. Sensors 2008, 8, 529-560.

11. Gallaun, H.; Zanchi, G.; Nabuurs, G.; Hengeveld, G.; Schardt, M.; Verkerk, P.J. EU-wide maps of growing stock and above-ground biomass in forests based on remote sensing and field measurements. Forest Ecol. Manag. 2010, 260, 252-261.

12. Blackard, J.A.; Finco, M.V.; Helmer, E.H.; Holden, G.R.; Hoppus, M.L.; Jacobs, D.M.; Lister, A.J.; Moisen, G.G.; Nelson, M.D.; Riemann, R.; et al. Mapping US forest biomass using nationwide forest inventory data and moderate resolution information. Remote Sens. Environ. 2008, 112, 1658-1677.

13. Kindermann, G.E.; McCallum, I.; Fritz, S.; Obersteiner, M. A global forest growing stock, biomass and carbon map based on FAO statistics. Silva Fenn. 2008, 42, 387-396.

14. Liu, S.N.; Zhou, T.; Shu, Y.; Dai, M.; Wei, L.Y.; Zhang, X. The estimating of the spatial distribution of forest biomass in china based on remote sensing and downscaling techniques. Acta. Ecologica. Sinica. 2012, 32, 2320-2330. (in Chinese)

15. Zheng, D.L.; Heath, L.S.; Ducey, M.J. Satellite detection of land-use change and effects on regional forest aboveground biomass estimates. Environ. Monit. Assess. 2008, 144, 67-79. 
16. Päivinen, R.; van Brusselen, J.; Schuck, A. The growing stock of European forests using remote sensing and forest inventory data. Forestry 2009, 82, 479-490.

17. Päivinen, R.; Lehikoinen, M.; Schuck, A.; Häme, T.; Väätäinen, S.; Kennedy, P.; Folving, S. Combining Earth Observation Data and Forest Statistics; EFI Research Report 14; European Forest Institute, Joint Research Centre-European Commission, EUR 19911 EN: Joensuu, Finland; Ispra, Italy, 2001; p. 101. Available online: http://fefr.org/files/attachments/publications/efi_rr14.pdf (accessed on 12 January 2014).

18. Sexton, J.O.; Song, X.P.; Feng, M.; Noojipady, P.; Anand, A.; Huang, C.Q.; Kim, D.H.; Collins, K.M.; Channan, S.; DiMiceli, C.; et al. Global, 30-m resolution continuous fields of tree cover: Landsat-based rescaling of MODIS vegetation continuous fields with lidar-based estimates of error. Int. J. Digit. Earth 2013, 6, 427-448.

19. Hansen, M.C.; Potapov, P.V.; Moore, R.; Hancher, M.; Turubanova, S.A.; Tyukavina, A.; Thau, D.; Stehman, S.V.; Goetz, S.J.; Loveland, T.R.; et al. High-Resolution Global Maps of 21st-Century Forest Cover Change. Science 2013, 342, 850-853.

20. De Jong, R.; Schaepman, M.E.; Furrer, R.; de Bruin, S.; Verburg, P.H. Spatial relationship between climatologies and changes in global vegetation activity. Glob. Chang. Biol. 2013, 19, 1953-1964.

21. Fang, J.Y.; Chen, A.P.; Peng, C.H.; Zhao, S.Q.; Ci, L. Changes in forest biomass carbon storage in China between 1949 and 1998. Science 2001, 292, 2320-2322.

22. Xu, X.L.; Cao, M.K.; Li, K.R. Temporal- spatial dynamics of carbon storage of forest vegetation in China. Prog. Geogr. 2007, 26, 1-10. (in Chinese)

23. Zhang, C.; Ju, W.; Chen, J.M.; Zan, M.; Li, D.; Zhou, Y.; Wang, X. China's forest biomass carbon sink based on seven inventories from 1973 to 2008. Clim. Chang. 2013, 118, 933-948.

24. Guo, Z.; Hu, H.; Li, P.; Li, N.; Fang, J. Spatio-temporal changes in biomass carbon sinks in China's forests from 1977 to 2008. Sci. China Life Sci. 2013, 56, 661-671.

25. Xiao, X.W. Study on Forest Biomass and Productivity in China. PhD Thesis, Northeast Forest University, Harbin, China, 2005. (in Chinese)

26. Piao, S.; Fang, J.; Zhu, B.; Tan, K. Forest biomass carbon stocks in China over the past 2 decades: Estimation based on integrated inventory and satellite data. J. Geophys. Res. 2005, 110, doi:10.1029/2005JG000014.

27. NASA Land Data Products and services. Available online: https://lpdaac.usgs.gov/products (accessed on 12 April 2013).

28. Verburg, P.H.; Neumann, K.; Nol, L. Challenges in using land use and land cover data for global change studies. Glob. Chang. Biol. 2011, 17, 974-989.

29. Herold, M.; Mayaux, P.; Woodcock, C.E.; Baccini, A.; Schmullius, C. Some challenges in global land cover mapping: An assessment of agreement and accuracy in existing $1 \mathrm{~km}$ datasets. Remote Sens. Environ. 2008, 112, 2538-2556.

30. Jia, S.; Zhu, W.; Lu, A.; Yan, T. A statistical spatial downscaling algorithm of TRMM precipitation based on NDVI and DEM in the Qaidam Basin of China. Remote Sens. Environ. 2011, 115, 3069-3079.

31. Dai, M.; Zhou, T.; Yang, L.L.; Jia, G.S. Spatial pattern of forest ages in China retrieved from national-level inventory and remote sensing imageries. Geogr. Res. 2011, 30, 172-184. (in Chinese) 
32. Chen, Q.; Xu, W.; Li, S.; Fu, S.; Yan, J. Aboveground biomass and corresponding carbon sequestration ability of four major forest types in south China. Chin. Sci. Bull. 2013, 58, 1551-1557.

33. Zheng, G.; Chen, J.M.; Tian, Q.J.; Ju, W.M.; Xia, X.Q. Combining remote sensing imagery and forest age inventory for biomass mapping. J. Environ. Manag. 2007, 85, 616-623.

34. Huang, L.; Liu, J.Y.; Shao, Q.Q.; Xu, X.L. Carbon sequestration by forestation across China: Past, present, and future. Renew. Sust. Energ. Rev. 2012, 16, 1291-1299.

35. State Forestry Administration. Atlas of Forest Resources of China; China Forestry Publishing House: Beijing, China, 2010. (in Chinese)

36. Li, H.K.; Lei, Y.C. Assessments of Forest Biomass and Carbon Storage in China; China Forestry Publishing House: Beijing, China, 2010. (in Chinese)

(C) 2014 by the authors; licensee MDPI, Basel, Switzerland. This article is an open access article distributed under the terms and conditions of the Creative Commons Attribution license (http://creativecommons.org/licenses/by/3.0/). 